\title{
O FEDERALISMO DEVE CONTRIBUIR COM A INTERPRETAÇÃO DOS DIREITOS CIVIS?'
}

\author{
MiCHAEL C. DORF ${ }^{\dagger}$
}

A Suprema Corte dos Estados Unidos (SCOTUS) programou ouvir, no final deste mês, as alegações do caso Gloucester County School Board v. G.G., em que se questiona se a polícia escolar distrital viola, ao proibir o uso de banheiro escolar masculino por parte de menino transgênero, o Título IX da Lei dos Direitos Civis (Civil Rights Act), uma lei federal que proíbe a discriminação sexual em escolas que recebem recursos federais. A Corte de Apelação do Quarto Circuito (U.S. Court of Appeals for the Fourth Circuit) decidiu que a postura da escola viola o Título IX, mas que sua decisão se apoia em uma política do Departamento de Educação da administração Obama -- formalizada mediante carta-consulta de janeiro de 2015 --que concluiu que o Título IX exige que estudantes possuam autorização para usar banheiros que correspondam às suas identidades de gênero. Quando os Ministros (justices) admitiram a revisão judicial da decisão do Quarto Circuito, esperavam que grande parte do caso focalizaria em questão de direito administrativo. Foi apropriado conceder deferência à política da carta-consulta?

Todavia, como a professora Joanna Grossman explicou na semana passada, a administração Trump, mencionando preocupações quanto aos direitos dos Estados, rejeitou a política da administração Obama. Em decorrência disso, na segunda-feira, a Suprema Corte devolveu o caso para a Corte de Apelação a fim de que realize juízo de reconsideração de sua decisão à luz do entendimento da nova administração.

Com a remoção da matéria de direito administrativo do caso sub judice, agora a Corte de Apelação focará sobre o próprio significado do Título IX. Nós podemos discernir quais argumentos que as partes provavelmente elaborarão, baseados nos argumentos que apresentaram à Suprema Corte.

O autor - Gavin Grimm - alegou que a política do Conselho escolar o discriminou sob o fundamento sexual, porque o termo sexo, usado no

\footnotetext{
${ }^{1}$ Should Federalism Play a Role in the Interpretation of Civil Rights? Publicado originalmente na Revista Verdict, disponível em: <https://verdict.justia.com/2017/03/08/federalismplay-role-interpretation-civil-rights-laws $>$. Traduzido por Antonio Guimarães Sepulveda, Doutorando em Direito pela Universidade do Estado do Rio de Janeiro, Pesquisador do Laboratório de Estudos Institucionais (LETACI). Revisado por Igor De Lazari, Mestre em Direito pela Universidade Federal do Rio de Janeiro, Pesquisador do Laboratório de Estudos Institucionais (LETACI) e Técnico Judiciário da Justiça Federal da 2ª Região.

+ Professor de Direito na Cornell Law School.
} 
Título IX, inclui identidade de gênero (como Grimm é menor de idade, a autuação do processo se refere a ele por suas iniciais, mas como ele fez inúmeras aparições sob seu verdadeiro nome, usá-lo não causará qualquer dano; de fato, a insistência em usar as iniciais poderia levar a se considerar que há algo de vergonhoso em ser transgênero).

Além disso, a opinião do amicus curiae na Suprema Corte, apresentada em meu nome e de outros três professores de Direito, defendeu que a política do Conselho que excluiu Grimm dos banheiros compartilhados e que o estigmatizou publicamente como inapto para usar os mesmos banheiros que todos os demais meninos, o discrimina com base no sexo no sentido mais literal possível: Grimm é excluído do banheiro masculino com base em sua anatomia sexual. Antiga regulação federal permite que instituições educacionais, financiadas com recursos federais, segreguem instalações sanitárias com base no sexo. Nossa opinião defende que enquanto tal segregação sexual possa ser inócua quando aplicada à maioria dos estudantes [cisgênero], a política do Conselho escolar contraria o Título IX (e é assim inválida) quando aplicada a estudantes transgêneros, porque inflige severo mal sobre eles, sem promover qualquer interesse institucional importante.

De outro lado, o Conselho escolar alega que o Congresso, que aprovou o Título IX, pretendeu com o termo "sexo" se referir ao que o amicus curiae chamou de "distinção fisiológica entre masculino e feminino", alertando que a decisão manteria de pé a "prática universalmente aceita de banheiros, vestiários, chuveiros, times e dormitórios separados baseados" em tais distinções. Como os leitores podem sem dúvida inferir a partir do fato de eu haver me manifestado favor de Grimm, considero que essa linha de argumentação é nada persuasiva - em particular porque, mesmo neste caso, é incoerente: Grimm sujeitou-se à terapia hormonal de testosterona e submeteu-se à cirurgia de reconstrução de tórax; em quase todos aspectos externamente observáveis, ele se apresenta fisiologicamente como homem. Além da confusão do cerne da política do Conselho escolar, não há razão para se pensar que suas repercussões desastrosas serão aprovadas com base apenas em um caso que se refere apenas a banheiros.

Em todo caso, leitores interessados em examinar mais a fundo os argumentos das partes deveriam consultar as respectivas petições na Suprema Corte. Ou aqueles premidos pelo tempo poderiam consultar a excelente análise da Professora Grossman publicada nesta coluna na semana passada.

Para o equilíbrio desta coluna, exploro a sugestão apresentada pela administração Trump de que esta questão deva ser decidida em nível estadual. Professora Grossman escreveu que esta sugestão "não faz 


\section{O FEDERALISMO DEVE CONTRIBUIR COM A INTERPRETAÇÃO DOS DIREITOS CIVIS?}

sentido neste contexto," e, como devo explicar, concordo. Entretanto, para entender o porquê disto, devemos primeiro reconhecer que em alguns outros contextos os direitos estaduais - ou, como a jurisprudência tipicamente se refere a interesse, o federalismo é relevante para a interpretação de leis federais.

\section{A LeGÍtima FunÇão do Federalismo NA INTERPRETAÇÃO LEGAL}

Algumas leis federais explicitamente contemplam participação de entes políticos estaduais na execução de seus objetivos. Leis federais, tais como Clean Air Act e Clean Water Act como também programas federais v.g., Medicaid e financiamentos para auto-estradas - são apenas alguns exemplos do assim chamado federalismo cooperativo. O governo federal estabelece uma ampla política e fornece a maioria ou todo o financiamento. Estados que optam por participar assumem importante função na implementação da política pública. Os direitos dos Estados são incorporados em tais programas.

Mesmo quando a lei federal não requer ou não incentiva a participação estadual em sua implementação, a Corte, ao interpretar enunciados normativos ambíguos desta lei, pode fazê-lo de modo a preservar a adaptabilidade dos Estados. Três tipos de fundamentos podem ser apresentados.

Primeiro, circunstâncias podem variar de lugar para lugar. Ao interpretar lei federal para permitir maior liberdade ao Estado e ao governo local, Cortes deixam em aberto as possibilidades que se adaptam a tais diferentes circunstâncias.

Segundo, mesmo que importantes circunstâncias estejam relativamente uniformes em todo país, interpretar lei federal para fornecer mais liberdade aos Estados e às localidades incentiva uma variedade de abordagens. Tal liberdade permite que cada Estado sirva como, famosamente chamou Justice Louis Brandeis, "um laboratório" para "novo experimento social e econômico, sem o risco para o resto do país".

Terceiro, a Constituição norte-americana cria um sistema de dupla soberania no qual o governo federal atua de acordo com seus poderes enumerados, enquanto que os Estados atuam segundo seus poderes exclusivos, quando não conflitem nem com a lei federal ou a com a Constituição. A Suprema Corte, por vezes, interpretou estritamente leis federais para evitar atribuir ao Congresso a intenção de ir até o fim da 
fronteira de seus poderes ou requereu uma clara declaração por parte do Congresso.

\section{Conflito de Valores e Federalismo}

Nenhum dos fatores até agora discutido parece abordar a questão se o Título IX permite ao Conselho escolar barrar um menino transgênero dos banheiros masculinos. Afinal, quando o Congresso aprova legislação protetora dos direitos e das liberdades civis - como tem acontecido desde a Reconstrução - ele necessariamente determina que nessas matérias a política nacional prevalece sobre diferenças regionais e sobre qualquer interesse sob experimentação.

Há, contudo, uma diferente espécie de argumento em favor dos direitos dos Estados com o qual, por vezes, alguém se depara e que parece ter animado a política da administração Trump. Quando normas sociais ficam para trás em relação às normas legais, Cortes, por vezes, hesitarão em exigir que as partes cumpram com a medida total das normas legais.

Por que as Cortes reduziriam as velas de sua nau dessa maneira? Como Alexander Hamilton observou no artigo Federalista 78, Cortes não detêm "nem o poder do cofre nem o poder da espada" e assim dependem, em última instância, dos atores políticos para cumprir seus julgamentos. Onde a opinião judicial de um assunto ultrapassa as normas sociais por amplíssima margem, o magistrado pode ser tentado a conter-se, mesmo se, ao fazê-lo, não realize o seu melhor julgamento.

Exemplos desse tipo de contenção são bem conhecidos no direito constitucional. Notoriamente, no caso que veio a ser conhecido como Brown II, a Suprema Corte não ordenou que os Estados que possuíam leis segregativas baseadas na raça dessegregassem suas escolas, em parte por medo de desencadear uma retaliação. Ao invés, a Corte ordenou que os Estados que praticavam a segregação jurídica (de jure segregation) se movessem para a dessegregação "com máxima urgência".

Divergindo da decisão da Suprema Corte que reputou constitucional o direito ao casamento homoafetivo, o presidente da Corte, Justice Roberts, expressou semelhante preocupação com aquela que orientou o caso Brown II. Entendeu que o direito ao casamento homoafetivo seria melhor aceito pelo Povo se ele o escolhesse democraticamente ao invés de (como entendeu o assunto) ser a ele imposto pelas Cortes.

\section{Por QUe O FEDERALISMO FALHA NO CASO}




\section{O FEDERALISMO DEVE CONTRIBUIR COM A INTERPRETAÇÃO DOS DIREITOS CIVIS?}

\section{GLOUCESTER COUNTY}

Contudo, esses dois principais exemplos de argumentos para ir devagar quando há conflito de valor, em última instância, comprometem ao invés de apoiar o argumento em defesa dos direitos dos Estados, como no caso Gloucester County.

Por um lado, a noção de que Cortes não devem se antecipar, em demasia, em relação à opinião pública em temas afetos a direitos e liberdades civis tem relativamente maior força em casos constitucionais do que em casos infraconstitucionais, tal como Gloucester County. Afinal, se uma decisão interpreta uma lei de modo que parcelas significativas do país achem problemática, Senadores e parlamentares de importantes Estados podem usar sua influência congressual para aprovar nova legislação.

Na verdade, a original denúncia de Grimm incluiu a alegação sobre a Cláusula da Igualdade de Proteção, prevista na Décima Quarta Emenda, não se limitando ao Título IX. Embora a Suprema Corte não admitindo o recurso apresentando de modo a decidir a matéria constitucional, a revisão poderia ocorrer com a devolução do processo à instância inferior ou em um futuro caso que envolvesse um diferente autor. E uma decisão, que envolva a política violadora da Constituição esposada pelo Conselho Escolar de Gloucester County no que tange ao uso de banheiros, não seria alterável por um ato do Congresso.

Com respeito às questões constitucionais, porém, a abordagem "não vá muito rápido" é extremamente falha. Considere o caso Brown II. Longe de querer uma margem de manobra para que a Corte assegurasse a eles dessegregar de maneira ordeira que permitisse que brancos sulistas aderissem à decisão, políticos, através do Sul, se engajaram em uma atuação de massiva resistência, enquanto que seus advogados se valeram da fórmula da "máxima urgência" como desculpa para o retardamento. Não foi antes da aprovação congressual do Civil Rights Act, de 1964 - que, entre outros assuntos, alocou recursos do Departamento de Justiça em tentativas de dessegregação - que substanciais mudanças começaram a ocorrer. Até essa data, uma nitidamente frustrada Suprema Corte declarou: "O tempo de 'máxima urgência' se esgotou".

Por outro lado, o medo do Presidente da Suprema Corte (Chief Justice) no sentido de que uma decisão em favor de casamento homoafetivo provocaria uma retaliação ou minaria apoio à igualdade matrimonial provou ser (até agora) injustificada. De acordo com a pesquisa Pew, a apoio remanesceu estável desde a decisão do verão de 2015. Segundo a pesquisa Gallup, o suporte à igualdade matrimonial tem crescido. 
Nada disso é para dizer que juízes deveriam simplesmente impor seus valores sobre uma relutante sociedade. Todavia, se juízes não são reisfilósofos, não são qualificados adivinhos que podem prever com alguma certeza quando o Povo se voltará contra a decisão versus quando o Povo será por ela guiado. Confrontados com tal incerteza, juízes e Ministros (justices) devem interpretar e aplicar o Direito o melhor possível. No caso em apreço, significa dizer: decidir em favor de Gavin Grimm e rejeitar o argumento da administração Trump dos direitos dos Estados. 